\title{
Sink-source and sink-sink relations during reproductive development in Lolium perenne $\mathrm{L}$.
}

\section{J.W. WARRINGA ${ }^{1,2, *}$ AND M.J. MARINISSEN ${ }^{1}$}

' DLO Research Institute for Agrobiology and Soil Fertility (AB-DLO), P.O. Box 14, NL-6700 AA Wageningen, the Netherlands

2 Wageningen Agricultural University, Department of Agronomy, Wageningen, the Netherlands

* Present address corresponding author (La Trobe University, School of Agriculture, Bundoora, Vic. 3083, Australia; fax: +61-3-9471-0224; e-mail: j.warringa@latrobe.edu.au)

Received 15 April 1997; accepted 29 September 1997

\begin{abstract}
Spaced plants of Lolium perenne $\mathrm{L}$. were labelled with ${ }^{13} \mathrm{C}$ at regular intervals from main ear emergence onwards in order to identify and measure the activity of source and sink organs during seed formation. The source activity of the various tiller groups within the plant roughly reflected the relative contributions of these groups to total plant dry mass. After anthesis there was little net exchange of ${ }^{13} \mathrm{C}$-label between the older and younger tiller groups. From main ear emergence onwards the source activity of the leaves of the reproductive tiller declined sharply, from $95 \%$ of total tiller photosynthesis to $16 \%$ at final harvest. The ear became the main assimilating organ on the flowering tiller as the leaves aged. During anthesis the stem was a stronger sink than the seeds. At final harvest $70 \%$ of the label was located in the stem, when fixed during anthesis. Water-soluble carbohydrates accumulated in the stem, up to $25 \%$ of dry matter. After anthesis the sink strength of the developing seeds increased and that of the stem decreased and the stem remained a net sink organ up to about mid-seed filling. Pre-anthesis assimilates contributed $14 \%$ to final seed and spikelet carbon, when correcting for the palea and lemma that are present before anthesis. It is shown that the stem is a temporary storage organ that can support seed filling. Yet only a small amount of the stem reserves was used by the seeds. In contrast to carbon, nitrogen was largely redistributed from the stem and leaves to the seeds. At final harvest $59 \%$ of the nitrogen in the flowering tiller was located in the seeds.
\end{abstract}

Keywords: ${ }^{13} \mathrm{CO}_{2}$ labelling, Lolium perenne $\mathrm{L}$., reproductive development, sink-source relations.

\section{Introduction}

Seed yields of crops of perennial ryegrass (Lolium perenne L.) are low and variable (Hebblethwaite et al., 1980; Elgersma, 1990), with only 10-20\% of the aboveground dry matter being harvested as seed. Competition between the seeds and 
growth of new tillers is thought to reduce seed yield (Hampton et al., 1983; Clemence \& Hebblethwaite, 1984; Griffith, 1992). Also the elongating stem might be a factor reducing seed yield, as it might compete with the developing ear (Ryle, 1970). These questions can be investigated by monitoring the activity of leaves, stem, seeds and younger tillers as carbon-source or carbon-sink.

Between the start of stem elongation and ear emergence the export of carbon assimilates from the youngest leaf on the main tiller to the stem increases strongly. The export to the younger tillers decreases from $39 \%$ to $20 \%$ of the total export and that to the roots decreases from 35\% to almost zero (Ryle, 1970; Parsons \& Robson, 1981). The fraction received by the developing ear increases, reaching $66 \%$ at ear emergence (Ryle, 1970).

After ear emergence the ear becomes the main source organ on the flowering tiller. In $L$. perenne the relative importance of the ear as a source organ increases during seed filling when the leaves age (Ong et al., 1978a; Clemence \& Hebblethwaite, 1984; Colvill \& Marshall, 1984). Ong et al. (1978a) found that the ear contributed $50 \%$ to the total amount of ${ }^{14} \mathrm{C}$-label assimilated by the whole tiller at mid-grain filling.

${ }^{14} \mathrm{C}$-labelling experiments in the field have shown that the amount of label exported to either the ear or the younger tillers varies. Clemence \& Hebblethwaite (1984) found that the fraction of assimilated ${ }^{14} \mathrm{C}$ exported to the younger tillers increased from $10 \%$ to $24 \%$ during seed development. In their experiment part of the stem was labelled and harvest took place after $24 \mathrm{~h}$. The export to the ear increased from $7 \%$ to $34 \%$. Colvill \& Marshall (1984) however, found much less label leaving the flowering tiller. When label was fixed by the main tiller at anthesis, at ripeness $16 \%$ of the label present was located in younger tillers and over $50 \%$ in the ear. According to Ong et al. (1978b) the flowering tiller exported only traces of ${ }^{14} \mathrm{C}$-label at anthesis. These reports agree on the increasing export of current assimilates to the ear, but disagree on the fraction exported to the younger tillers. Furthermore, the role of stem reserves is not clear. This could be clarified by studying one genotype under greenhouse conditions, in order to reduce variation between plants.

Labelling whole plants with ${ }^{13} \mathrm{CO}_{2}$ enables one to follow the distribution of carbon through the plant (Yamagata et al., 1987; Svejcar et al., 1990) and thus to quantify the distribution between and within tillers of ${ }^{13} \mathrm{C}$-label assimilated at regular intervals from ear emergence onwards. Monitoring the distribution of ${ }^{13} \mathrm{C}$-label will give a qualitative pattern of the source-sink and sink-sink relations within the plant. ${ }^{13} \mathrm{C}$-labelling was also used to measure the source activity, by viewing the fraction of ${ }^{13} \mathrm{C}$-label fixed by a plant part as a measure of the actual carbon flux through that source (Farrar, 1992).

The objectives of the study were: to measure the relative activity of the source organs from ear emergence onwards, to determine changes in the pattern of sink-sink relations in the reproductive plant from ear emergence onwards, and to estimate the contribution of carbon fixed before anthesis to final seed carbon. 


\section{Materials and methods}

\section{Plant growing conditions}

Vegetative tillers of $L$. perenne were clonally propagated on nutrient solution (Steiner, 1984). To obtain flowering tillers, one tiller per pot was vernalised for 14 weeks at $7 \pm 1{ }^{\circ} \mathrm{C}$, at a photoperiod of $8 \mathrm{~h}$ and approximately $8 \mathrm{~W} / \mathrm{m}^{2}$ (PAR) using both fluorescent and incandescent light. This tiller will be referred to as the main tiller. After vernalisation the plants were transferred to a greenhouse at $15^{\circ} \mathrm{C}$ with the shading screen down and allowed to acclimatise for one week. The plants were then transferred to 1.751 pots filled with a peaty soil. Per plant $240 \mathrm{mg} \mathrm{N}, 110 \mathrm{mg}$ $\mathrm{P}_{2} \mathrm{O}_{5}$ and $180 \mathrm{mg} \mathrm{K} \mathrm{K}_{2} \mathrm{O}$ was supplied. In the greenhouse natural daylength was extended to $17 \mathrm{~h}$ with incandescent bulbs (approximately $1.7 \mathrm{~W} / \mathrm{m}^{2}$ ). For $12 \mathrm{~h}$ per day supplemental lighting was provided by high pressure sodium lamps (Philips, AGRO SON-T, $400 \mathrm{~W}$ ). The average daily incoming radiation at plant height was $2.7 \mathrm{MJ} / \mathrm{m}^{2}$ $(400-700 \mathrm{~nm})$. The average day and night temperatures were $23^{\circ} \mathrm{C}$ and $17^{\circ} \mathrm{C}$ respectively. Iron wire was used to prevent the flowering tillers from lodging.

\section{Experimental design}

One clone ( $\mathrm{B} 1$, selected from the Dutch cultivar Barlet) was used and the plants were grown in a randomised block design. Four other clones were used in the border rows and as pollinators. The time schedule of labelling and the number of plants used are shown in Table 1. After each ${ }^{13} \mathrm{CO}_{2}$ feeding four labelled plants were harvested immediately and at each subsequent ${ }^{13} \mathrm{CO}_{2}$ feeding until 42 days after main ear emer-

Table 1. Growth stage, time schedule of labelling and number of plants used.

\begin{tabular}{|c|c|c|c|c|c|}
\hline \multirow[b]{2}{*}{$\begin{array}{l}\text { Growth stage } \\
\text { main ear }\end{array}$} & \multicolumn{3}{|c|}{ Pulse-chase labelling } & \multirow{2}{*}{$\begin{array}{l}\text { Number } \\
\text { of control } \\
\text { plants }\end{array}$} & \multirow{2}{*}{$\begin{array}{l}\text { Number } \\
\text { of plants } \\
\text { labelled for } \\
\text { ten minutes }\end{array}$} \\
\hline & $\begin{array}{l}\text { Days after } \\
\text { main ear } \\
\text { emergence } \\
\text { (DAEE) }\end{array}$ & $\begin{array}{l}\text { Number } \\
\text { of groups } \\
\text { labelled } \\
\text { ( } 4 \text { plants/group) }\end{array}$ & $\begin{array}{l}\text { Harvest } \\
\text { dates groups } \\
\text { (DAEE) }\end{array}$ & & \\
\hline $\begin{array}{l}\text { Main ear } \\
\text { emergence }\end{array}$ & 0 & 6 & $\begin{array}{l}0,14,21,28 \\
35,42\end{array}$ & 15 & 5 \\
\hline Onset of anthesis & 14 & 5 & $14,21,28,35,42$ & 15 & 5 \\
\hline Mid-anthesis & 21 & 4 & $21,28,35,42$ & 15 & 5 \\
\hline End of anthesis & 28 & 3 & $28,35,42$ & 15 & 5 \\
\hline $\begin{array}{l}3 \text { Weeks after } \\
\text { onset of anthesis }\end{array}$ & 35 & 2 & 35,42 & 15 & 5 \\
\hline $\begin{array}{l}4 \text { Weeks after } \\
\text { onset of anthesis }\end{array}$ & 42 & - & - & 15 & 5 \\
\hline
\end{tabular}

\footnotetext{
I Plants were labelled one day later than the pulse-chase labelling.
} 
gence (DAEE), the final harvest. This means that after each ${ }^{13} \mathrm{CO}_{2}$ feeding the label could be chased for various periods until 42 DAEE. At each ${ }^{13} \mathrm{CO}_{2}$ feeding 15 unlabelled control plants (three plants times five replicates) were harvested to determine dry matter accumulation and distribution, water-soluble carbohydrate concentration, nitrogen concentration and control values of the ${ }^{13} \mathrm{C}$ stable isotope ratios $\left(\delta^{13} \mathrm{C}\right)$ in the plant organs studied.

\section{${ }^{13} \mathrm{CO}_{2}$ pulse-chase experiments}

The first ${ }^{13} \mathrm{CO}_{2}$ feeding was applied when in $50 \%$ of the plants the top of main ear had emerged from the leaf sheath. Whole plants were labelled in a closed system consisting of a perspex chamber $(80 \times 80 \times 80 \mathrm{~cm})$ connected to a cooling device with a fan that kept the temperature at $20 \pm 1^{\circ} \mathrm{C}$ and also homogenised the air. The plants for the various harvest dates were randomised inside the labelling chamber. The light intensity during labelling was approximately $110 \mathrm{~W} / \mathrm{m}^{2}$ (PAR) at plant height provided by metal halide lamps (Philips HPI/T, $400 \mathrm{~W}$ ). ${ }^{13} \mathrm{CO}_{2}$ was produced by adding a surplus of $0.5 \mathrm{M}$ sulphuric acid to $\mathrm{Na}_{2}{ }^{13} \mathrm{CO}_{3}$ (99 atom\%, Campro Scientific, Elst, the Netherlands). The amount of $\mathrm{Na}_{2}{ }^{13} \mathrm{CO}_{3}$ used at each ${ }^{13} \mathrm{CO}_{2}$ feeding was aimed at achieving sufficiently enriched plant organs $\left(\delta^{13} \mathrm{C}>0\right)$ until the end of the desired chase period, hereby taking into account an estimated lowering of the ${ }^{13} \mathrm{C} /{ }^{12} \mathrm{C}$ isotope ratio through plant growth and respiration. Each ${ }^{13} \mathrm{CO}_{2}$ feeding period was ended when the ${ }^{12} \mathrm{CO}_{2}$ concentration in the chamber, measured by an infrared gas analyser had fallen to $100-200 \mu \mathrm{mol} / \mathrm{mol}$.

\section{Fixation of label by the source organs}

In this experiment the fraction of label fixed by a plant part after labelling for ten minutes was considered to be a measure of the source activity of that part. Results from a pilot experiment, in which plants were labelled at mid-anthesis for ten minutes, had shown that the leaf blades exported $47 \%$ of the label within one hour. This means that labelling for a longer period would definitely underestimate the fixation by the leaves. Immediately after ${ }^{13} \mathrm{CO}_{2}$ feeding the plants were harvested, and the dissected plant parts placed on ice to minimise respiratory losses before drying. At the first harvest only the part of the ear that had appeared was separated from the stem. At the other harvests the spikelets and rachis were separated.

\section{Harvest procedure}

At each harvest the plants were divided into four groups of tillers (Figure 1): 1) the main tiller, 2) a homogeneous group of younger reproductive tillers, 3) tillers which had at least one fully emerged leaf, and 4) small tillers with a partly emerged first leaf and tillers present inside the leaf sheaths of the tillers in the first two groups. The second group of tillers consisted of all tillers other than the main tiller that were present one week after the end of vernalisation. These tillers were marked at that moment. The group 3 and group 4 tillers were not marked. 


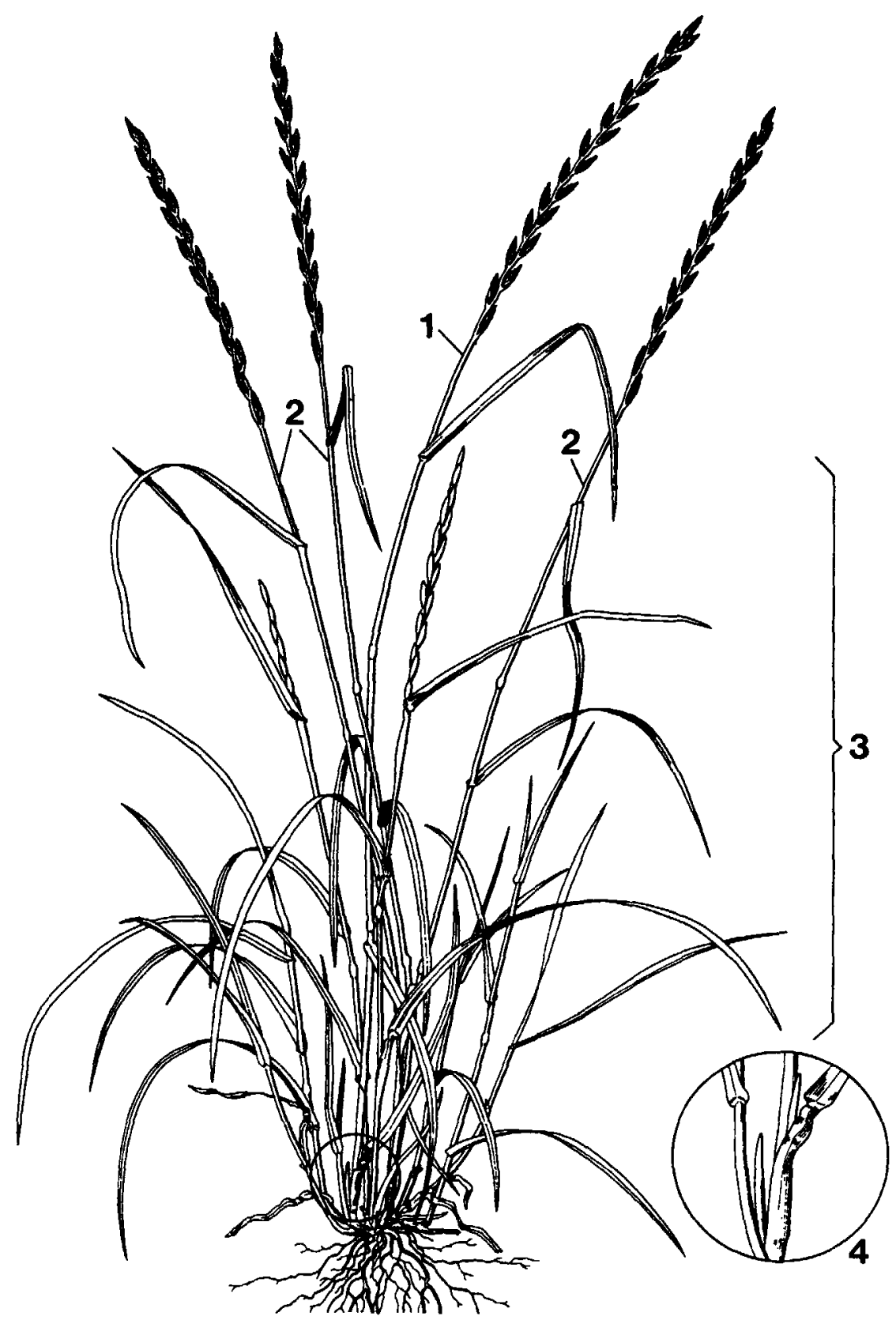

Figure 1. Representation of a flowering Lolium perenne plant, divided into four groups of tillers: 1) main tiller, 2) a homogeneous group of younger flowering tillers, 3) tillers with at least one fully emerged first leaf and 4) small tillers present inside the leaf sheaths of the older flowering tillers and tillers with a partly emerged first leaf. (From: Warringa \& Kreuzer, 1996.) 
The main tiller and group 2 tillers were divided into stem + rachis, green and yellow leaf and spikelets. At the first harvest partly emerged ears were taken out of the leaf sheath. At the last two harvests the seeds and empty florets of the main ear were separated, but not of the group 2 ears. The ears were stored at $-20^{\circ} \mathrm{C}$ until the number of seeds and empty florets were counted under a binocular microscope. Small top florets in a spikelet were regarded as non-fertile and omitted if they did not protrude beyond the subtending floret. The dry mass of the various plant parts was determined after drying at $70^{\circ} \mathrm{C}$ for $48 \mathrm{~h}$. Roots were not harvested.

\section{Chemical analyses}

For the determination of water-soluble carbohydrates (WSC) the plant parts were ground and extracted in water at $100^{\circ} \mathrm{C}$ for 15 minutes. Total reducing sugars were measured colorimetrically after hydrolysis in sulphuric acid $(0.23 \mathrm{M})$ with an automatic analysis device (Bran \& Lübbe Analyzing Technologies, Inc., Elmsford, N.Y., USA). Starch was determined titrimetrically after enzymatic hydrolysis (Williams, 1984).

The ${ }^{13} \mathrm{C}$ isotope ratio $\left(\delta^{13} \mathrm{C}\right)$, carbon concentration and nitrogen concentration were determined with a continuous-flow isotope-ratio mass spectrometer (Roboprep-CN) and Tracermass (Stable Isotope Analyser) (Europe Scientific, Crewe, UK.). All replicates were pooled before chemical analysis.

\section{Calculations}

Dry weight was analysed in an analysis of variance using the GENSTAT statistical package (Payne et al., 1987). To calculate the amount of ${ }^{13} \mathrm{C}$-label in the different plant organs the dry weight and the ${ }^{13} \mathrm{C}$ atom excess of the labelled plants were used (Svejcar et al., 1990; Boutton, 1991). These results were expressed as a percentage of the total amount of ${ }^{13} \mathrm{C}$-label present at that harvest, in the whole plant shoot or in a tiller.

The relative contribution of carbon fixed before anthesis to final carbon in the seeds of the main tiller and the spikelets in the group 2 tillers was estimated using the method described by Bidinger et al. (1977). The relative contribution to final seed and spikelet carbon of a growth interval between two ${ }^{13} \mathrm{CO}_{2}$ feedings was estimated using the fraction of the ${ }^{13} \mathrm{C}$-label present in the seeds and spikelets at final harvest. The average fraction of the two enclosing ${ }^{13} \mathrm{CO}_{2}$ feedings was used. This fraction (FS) was then weighted using the changes in plant dry weight during this growth interval (equation 1; Hall et al., 1989).

$$
\Delta \mathrm{W}_{1} \cdot \overline{\mathrm{FS}}_{1} /\left[\left(\Delta \mathrm{W}_{1} \cdot \overline{\mathrm{FS}}_{1}\right)+\left(\Delta \mathrm{W}_{2} \cdot \overline{\mathrm{FS}}_{2}\right)\right]
$$

In equation $1 \Delta \mathrm{W}$ denotes the change in plant dry weight, $\overline{\mathrm{FS}}$ is the mean fraction of label in the seeds for a given period, and the subscripts 1 and 2 refer to the pre- and post-anthesis periods, respectively. The increase in plant dry weight was determined from the plant dry weight curve fitted with a negative exponential equation. 


\section{Results}

\section{Tiller growth and development}

Because spaced plants were used, a hierarchy of tillers of different ages developed. Each plant had on average $7.6 \pm 2.2$ group 2 tillers. The number of group 3 tillers increased from $16 \pm 4$ at the first harvest to $43 \pm 14$ at the final harvest. As group 4 tillers developed they were reclassified as group 3 tillers by the next harvest, and therefore the number of group 4 tillers decreased from $8 \pm 4$ to $0.6 \pm 0.8$ per plant. The main ear started to flower at $41 \pm 1$ days after the end of vernalisation, the ears in group 2 started to flower several days later. At final harvest $44 \%$ of the group 3 tillers had an ear.

Figure 2 shows that total plant dry weight reached a plateau at 35 DAEE. The contribution of group 3 tillers to total plant dry weight increased from $25 \%$ at main ear emergence to $64 \%$ at final harvest. The dry weight of the group 4 tillers was negligible and decreased from $50 \mathrm{mg}$ at main ear emergence to $4 \mathrm{mg}$ at final harvest.

The main ear had $22 \pm 1$ spikelets and $212 \pm 20$ florets per ear. Seed set was $75 \%$ and the seed yield per ear $223 \pm 54 \mathrm{mg}$ with an average seed dry weight of $1.4 \pm 0.2 \mathrm{mg}$. The pattern of dry matter distribution within both the main tiller and the average group 2 tiller was similar, but the main tiller was heavier and some days advanced in development (Figure 3). At final harvest the relative contribution of the spikelets to total tiller dry weight was $31 \%$ for the main tiller and $28 \%$ for the average group 2 tiller. The corresponding figures for the contribution of the stem were $45 \%$ and $46 \%$.

\section{Water-soluble carbohydrates (WSC), starch and nitrogen}

The distribution pattern of the WSC and nitrogen amount were similar for both the main tiller and the group 2 tillers. Only the results of the main tiller are shown. From main ear emergence onwards the amount of WSC in the stem increased sharply (Figure 4). At final harvest the WSC concentration had risen to about $26 \%$ of the dry

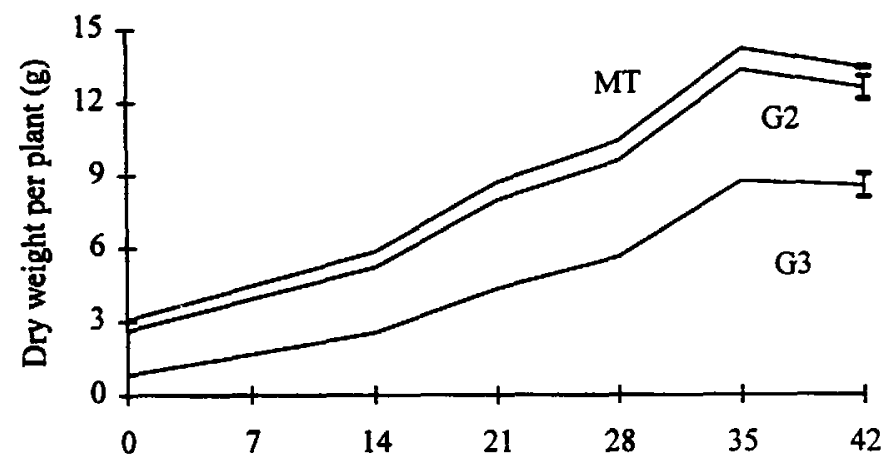

Days after main ear emergence
Figure 2. The cumulative dry weight of plants of Lolium perenne, divided into main tiller (MT), group 2 and group 3 tillers (see Figure 1). Vertical bars indicate LSD (0.05) values for a tiller group over time. 


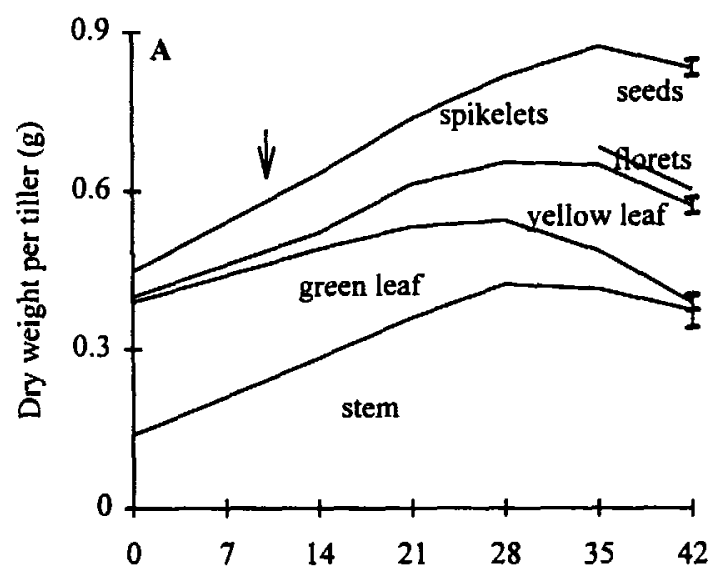

Figure 3. The cumulative dry weight of the main tiller (A) and of the average group 2 tiller (B) in plants of Lolium perenne. Onset of anthesis is indicated by the arrows. Vertical bars indicate LSD (0.05) values of the various plant organs over time.

Days after main ear emergence

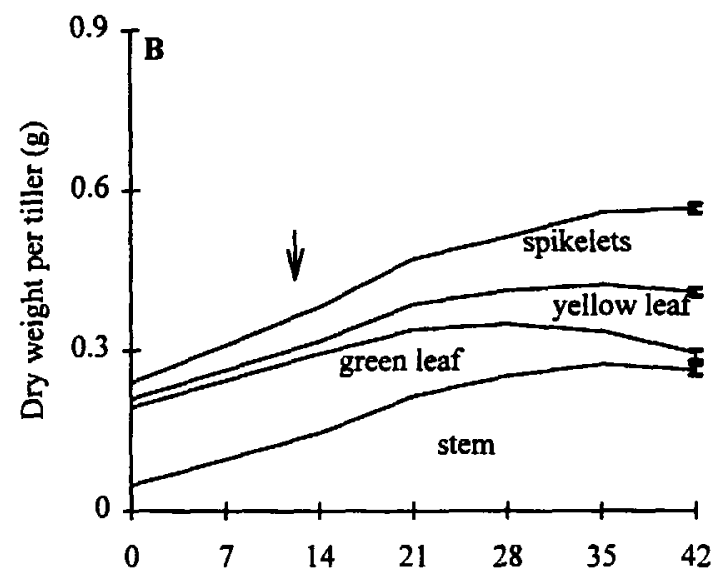

Days after main ear emergence

weight in the main stem and $24 \%$ in the stems of the group 2 tillers. Between main ear emergence and the beginning of anthesis both concentration and amount of WSC in the leaves and the spikelets decreased. After onset of anthesis the amount of WSC in the leaves and the spikelets increased again. From the moment the seeds started to accumulate starch the amount of WSC in the spikelets declined. The seeds in the main ear had a starch concentration of $30 \%$ at 35 DAEE and $36 \%$ at final harvest. The WSC concentration of the whole plant increased from $11 \%$ at main ear emergence to $17 \%$ at final harvest.

The amount of nitrogen decreased in all the main tiller organs except the spikelets. At final harvest $59 \%$ of the nitrogen in the main tiller was located in the seeds, which had a nitrogen concentration of $2.1 \%$. Total plant nitrogen concentration fell 


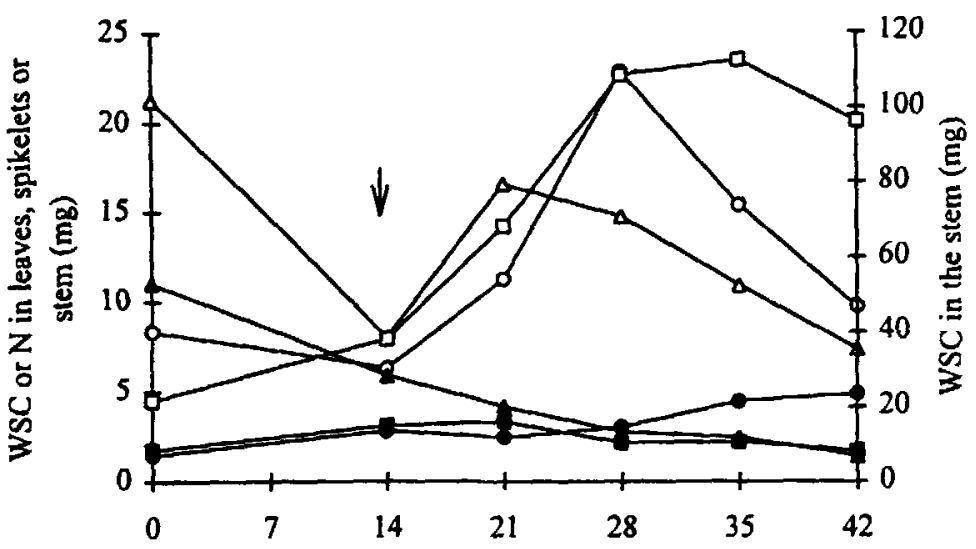

Days after main ear emergence

Figure 4. Changes in the amount of water-soluble carbohydrates, WSC (open symbols) and nitrogen (closed symbols) in the spikelets, stem and leaves of the main tiller over time after main ear emergence in plants of Lolium perenne. $(O, O)$ spikelets; $(\square, \square)$ stem; $(\Delta, \Delta)$ leaves. Arrow indicates onset of anthesis.

from $2.7 \%$ at main ear emergence to $1.0 \%$ at final harvest.

Nitrogen was also redistributed between tiller groups. From main ear emergence until the end of flowering of the main ear, at $28 \mathrm{DAA}$, the fraction of nitrogen in the tillers of group 3 increased from $27 \%$ to $67 \%$ on a whole plant basis. The fraction of nitrogen in the main tiller fell from $17 \%$ to $5 \%$ and that in the tillers in group 2 fell from $54 \%$ to $28 \%$.

\section{Fixation and distribution of ${ }^{13} \mathrm{C}$-label between tiller groups}

The absolute amount of ${ }^{13} \mathrm{C}$-label fixed in ten minutes by the whole plant rose from $0.52 \mathrm{mg}$ at main ear emergence to $0.98 \mathrm{mg}$ at $29 \mathrm{DAEE}$ and then declined to $0.6 \mathrm{mg}$ at 43 DAEE. These values, in the same order, represent $0.9 \%, 0.8 \%$ and $0.5 \%$ of the amount of label supplied.

Figure 5 shows the relative ${ }^{13} \mathrm{C}$-fixation by the different tiller groups immediately after labelling for ten minutes and the relative distribution at final harvest after pulse-chase labelling for $1.5-2.5 \mathrm{~h}$. The difference between the two lines gives information about the redistribution of label between the tiller groups. The fraction of total assimilated ${ }^{13} \mathrm{C}$-label that was fixed by the main tiller and group 2 tillers decreased during plant development, whereas the fraction fixed by the group 3 tillers increased sharply (Figure 5). The small group 4 tillers fixed only traces of ${ }^{13} \mathrm{C}$-label $(<1 \%)$. These results roughly reflected the pattern of relative contributions to total plant dry weight of those tiller groups (Figure 2).

Net exchange of ${ }^{13} \mathrm{C}$-label between the tiller groups occurred mainly after labelling at 15 and 22 DAEE, i.e. during anthesis. In the last two ${ }^{13} \mathrm{CO}_{2}$ feedings there was little net exchange of ${ }^{13} \mathrm{C}$-label between the tiller groups (Figure 5). 


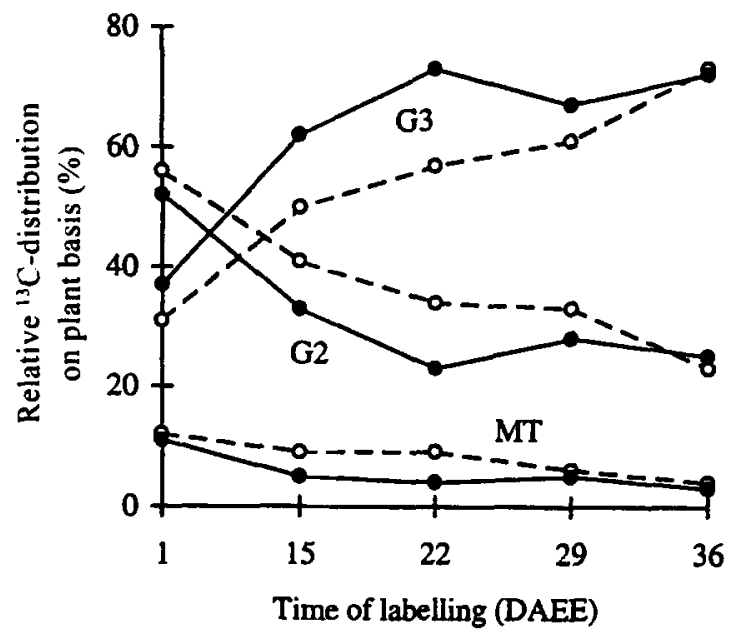

Figure 5. The relative fixation of ${ }^{13} \mathrm{C}$ label after labelling for ten minutes (O) and the relative distribution at final harvest (42 DAEE) after labelling for 1.5-2.5 $\mathrm{h}(O)$ between groups of tillers in Lolium perenne plants. $\mathrm{MT}=$ main tiller, G2 = group 2 tillers, G3 = group 3 tillers. The time of labelling is indicated on the horizontal axis.

\section{Fixation and distribution of ${ }^{13} \mathrm{C}$-label within the flowering tiller}

In both the main tiller and the average group 2 tiller the fraction of ${ }^{13} \mathrm{C}$-label fixed by the leaves declined sharply from more than $95 \%$ at main ear emergence to $16 \%$ at final harvest. The fraction of ${ }^{13} \mathrm{C}$-label fixed by the stem increased steadily, while that of the ear rose to a plateau of $30-40 \%$ after anthesis (Figure 6).

The relative distribution of ${ }^{13} \mathrm{C}$-label within the main tiller and within the group 2 tillers was similar, therefore only the results of the former are shown (Figure 7). The ${ }^{13} \mathrm{C}$-label in the leaves declined sharply between each ${ }^{13} \mathrm{CO}_{2}$ feeding and final harvest both in relative and absolute terms. When the ${ }^{13} \mathrm{C}$-label was fixed later in development, more was exported to the spikelets and less to the stem. But the distribution of ${ }^{13} \mathrm{C}$-label fixed during early anthesis (14 DAEE) was in contrast to this trend.

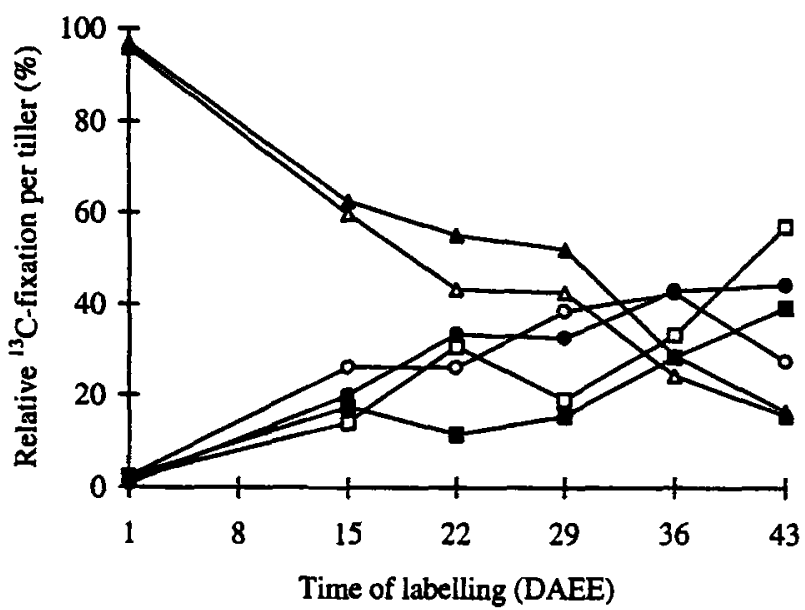

Figure 6. The relative fixation of ${ }^{13} \mathrm{C}$-label by the ear, stem and leaves of the main tiller (open symbols) and the average group 2 tiller (closed symbols) in plants of Lolium perenne after labelling for 10 minutes. Time of labelling is indicated on the horizontal axis. $(O, O)$ spikelets; $(\square, \square)$ stem; $(\triangle . \Delta)$ leaves. 
Then the leaves exported to the stem and not to the spikelets. From labelling at 28 DAEE onwards the leaves exported only to the spikelets.

Until about 28 DAEE the stem imported ${ }^{13} \mathrm{C}$-label from the leaves. An increasing
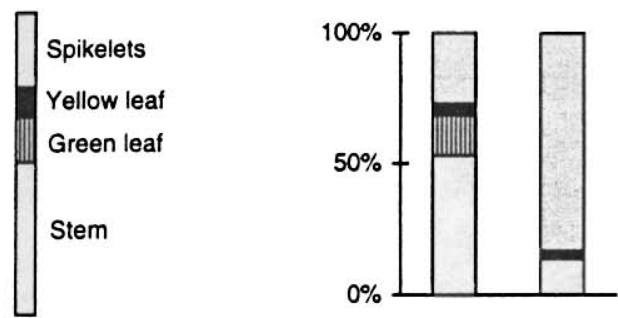

35

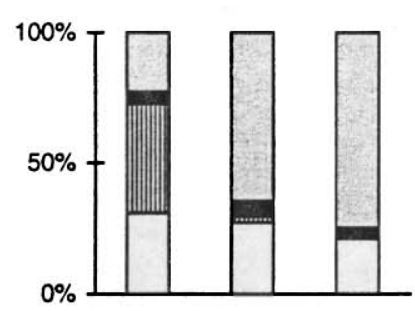

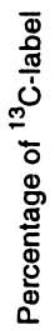

21
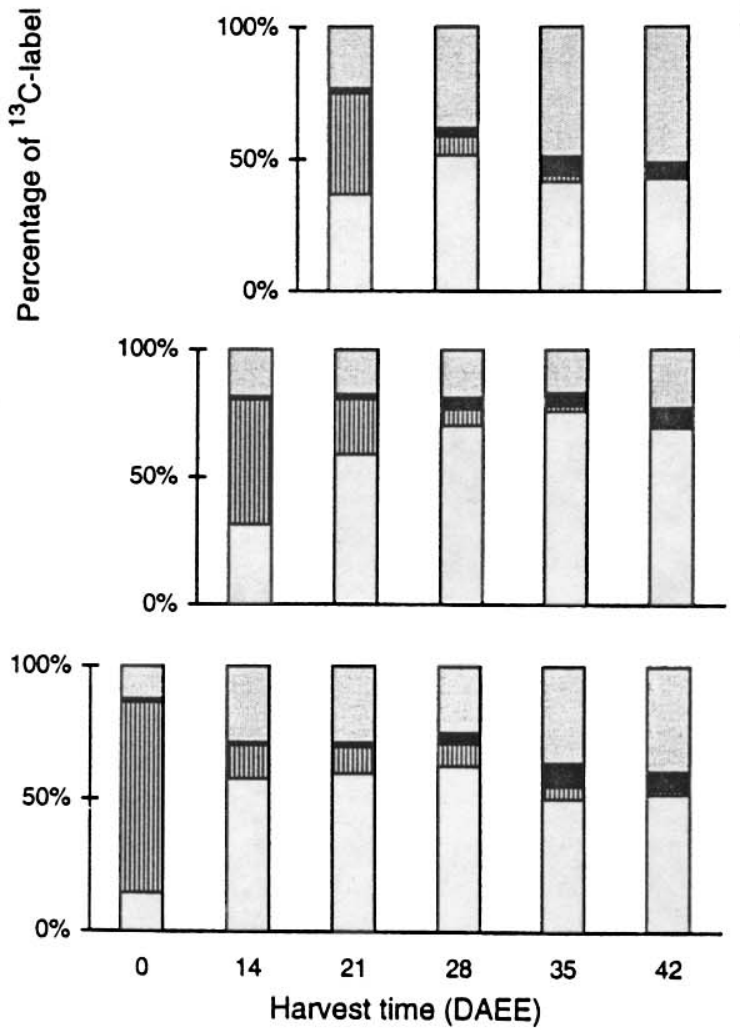

Figure 7. The relative distribution of ${ }^{13} \mathrm{C}$-label within the main tiller of plants of Lolium perenne, between spikelets, green and yellow leaf and stem. Plants were pulselabelled at $0,14,21,28$ and 35 days after main ear emergence (DAEE), as indicated next to the graphs. Plants were harvested regularly up to the final harvest ( 42 $\mathrm{DAEE})$, as indicated on the horizontal axis. 
fraction of the ${ }^{13} \mathrm{C}$-label fixed by the stem after 28 DAEE was exported to the spikelets. In the first ${ }^{13} \mathrm{CO}_{2}$ feeding some of the ${ }^{13} \mathrm{C}$-label imported by the stem was redistributed after $28 \mathrm{DAEE}$ to the spikelets. The fraction of ${ }^{13} \mathrm{C}$-label in the stem decreased by about $10 \%$.

Towards later stages of development label fixed by the stem and leaves was rapidly distributed to the spikelets. After labelling at 35 DAEE the fraction of label in the spikelets of the main tiller increased from $27 \%$ to $83 \%$ at final harvest one week later (Figure 7) and in the group 2 tillers it increased from $35 \%$ to $84 \%$.

The distribution of ${ }^{13} \mathrm{C}$-label at final harvest within the spikelets of the main tiller between empty florets and the seeds shifted towards the seeds when fixed later during development. The fraction of ${ }^{13} \mathrm{C}$-label in the seeds, as a percentage of the total amount in the spikelets, increased from $72 \%$ after labelling at main ear emergence to more than $96 \%$ in the last ${ }^{13} \mathrm{CO}_{2}$ feeding.

\section{Estimation of the relative contribution to seed carbon of pre-anthesis assimilates}

Using equation 1 the estimated pre-anthesis contribution to final carbon in the seeds of the main tiller and the spikelets in the group 2 tillers was $40 \%$. This is, however, an over-estimation because the palea and lemma are present already at anthesis. They contribute about $26 \%$ to total seed dry weight in the genotype used (Warringa et al., 1998). This means that only $14 \%$ of the final seed and spikelet carbon was redistributed after anthesis.

\section{Discussion}

In the present study growth analysis was combined with pulse-chase labelling of whole plants in order to estimate the contribution of pre-anthesis assimilates to final carbon in the seeds. A flaw of this method is that redistribution from the roots is ignored (Bidinger et al., 1977; Schnyder, 1993). However, loss of leaves after anthesis which can be a problem in field experiments, did not occur in the greenhouse.

Furthermore, monitoring the distribution of ${ }^{13} \mathrm{C}$-label resulted in a qualitative estimate of the changes in sink-sink relations within the plant. Under the assumption that ${ }^{13} \mathrm{C}$ will behave similar to ${ }^{12} \mathrm{C}$ in the plant an indication of the relative changes in sink strength (e.g. stem vs. ear) is obtained. Carbon input lost through respiration is not measured. Ideally, steady-state labelling is used which would enable a quantification of the partitioning of carbon within the plant (Yamagata et al., 1987; Schnyder, 1993).

\section{Fixation of ${ }^{13} \mathrm{C}$-label and its distribution between tiller groups}

The increase in plant dry weight from main ear emergence onwards was mainly due to the increase in number and dry weight of the group 3 tillers (Figure 2). This pattern was reflected by the increasing source activity of these tillers as development proceeded (Figure 5). 
During anthesis of the main tiller the group 3 tillers were a net sink (Figure 5), because of their increasing number, as the relative amount of ${ }^{13} \mathrm{C}$-label per individual tiller hardly changed (data not shown). During the seed filling phase, after 28 DAEE, there was only a minor net exchange of ${ }^{13} \mathrm{C}$-label between the tiller groups and tillers seemed mutually independent.

These results agree with Colvill \& Marshall (1984), who found $16 \%$ of the label to be located in the younger tillers at ripeness when fixed during anthesis. Clemence \& Hebblethwaite (1984) however, found that the fraction of the assimilated label exported from the main tiller to the younger tillers within $24 \mathrm{~h}$ increased up to $24 \%$ during seed development. And according to Ong et al. (1978b) the flowering tiller exports only traces of label at anthesis. Clemence \& Hebblethwaite (1984) grew plants under high nitrogen availability compared with the other studies mentioned and lodging was severe (Marshall, 1985). This demonstrates that sink strength of the younger tillers is affected by external conditions.

Several authors (Hampton et al., 1983; Clemence \& Hebblethwaite, 1984; Griffith, 1992) have suggested that younger tillers compete with the seeds for assimilates. This seems unlikely, given the large amount of carbohydrates in the stem (Figure 4; Spiertz \& Ellen, 1972). Indeed, stem carbohydrate reserves even increased concomitantly with the large increase in number of group 3 tillers (Figures 2, 4).

Not only ${ }^{13} \mathrm{C}$-label but also some nitrogen was redistributed from the flowering tillers to the group 3 tillers. Whether or not an increased sink strength of younger tillers (carbohydrates and/or nitrogen) can depress seed yields remains to be seen. Tillering and growing conditions need to be manipulated in order to investigate this.

\section{Fixation and distribution of ${ }^{13} \mathrm{C}$-label within the flowering tiller}

The source activity of the leaves of both the main tiller and average group 2 tiller declined sharply after main ear emergence, while that of the ear and stem increased (Figure 6). The reduction in source activity of the leaves was due to an $80-90 \%$ reduction in green leaf weight (Figure 3 ) that was accompanied by the nitrogen concentration of the remaining green leaf falling from $3.5 \%$ to $1.1 \%$. Generally a positive correlation between leaf nitrogen and carbon-assimilation capacity is found (Evans, 1989; Sinclair \& Horie, 1989).

In accordance with results of Ong et al. (1978a) and Clemence \& Hebblethwaite (1984) we found an increasing source activity of the ear during seed development as the leaves aged. The former found that the source activity of the ear decreases quickly at ripeness (Ong et al., 1978a); this agrees with results for the main tiller shown in Figure 6. Our results confirm that the ear is the main source organ on the flowering tiller (Ong et al., 1978a; Clemence \& Hebblethwaite, 1984; Colvill \& Marshall, 1984).

Up to about 28 DAEE the stem remained a net sink organ (Figure 7). During anthesis the stem was a stronger sink than the spikelets, i.e., carbon from the leaves was imported by the stem and not by the spikelets. After anthesis the sink strength of the developing seeds increased and exceeded that of the stem. The stem then became a net source organ. Our results confirm the role of the stem as a temporary storage 
organ (Colvill \& Marshall, 1984; Griffith, 1992) that can support seed filling.

Assimilates exported from the leaves enter the stem, which then either stores them, uses them for growth or exports them. The increase in amount of WSC in the stem between ear emergence and anthesis, together with the decrease in the leaves and spikelets (Figure 4), indicates that the elongating stem used more assimilates than it produced. At that time the stem was still elongating and increasing in dry weight (Figure 3). During stem elongation the stem is the dominant sink on the flowering tiller (Ryle, 1970), whereas young seeds are a very weak sink.

It is not clear if this pattern of assimilate distribution reduces the number of seeds. Under reduced light intensity during stem elongation, and limited assimilate availability, the number of florets per spikelet is reduced (Ryle, 1967). However, abortion under non-stress conditions is thought to have genetic and cytological causes associated with outbreeding and not to be caused by competition for assimilates (Elgersma \& Sniezko, 1988; Marshall \& Ludlam, 1989).

In contrast to WSC, nitrogen did not accumulate in the stem or the leaves but was translocated to the seeds in such a way that at final harvest most of the nitrogen in the flowering tiller was located in the seeds (Figure 4). Accumulation of nitrogen in seeds is thought to be regulated independently of that of carbon (Jenner, 1980; Swank et al., 1982).

\section{Estimation of the relative contribution to seed carbon of pre-anthesis assimilates}

Assimilates fixed before anthesis contributed about $14 \%$ to final seed and spikelet carbon, when correcting for the palea and lemma that develop before anthesis and constitute $26 \%$ of the final seed dry weight. Expressed on the basis of the caryopsis itself (seed without palea and lemma) this would mean a contribution of assimilates fixed before anthesis of about $19 \%$. In wheat and barley about $5-15 \%$ is accounted for by carbohydrates stored prior to anthesis under non-stressed conditions. Wheat seeds are harvested without the palea and lemma but in barley the husk constitutes about $8 \%$ of the final seed dry weight (Bidinger et al., 1977). The contribution of pre-anthesis assimilates to seed carbon seems somewhat higher in $L$. perenne than in wheat and barley.

Under conditions unfavourable for photosynthesis such as drought this contribution increases to 27-44\% (Bidinger et al., 1977; Austin et al., 1980; Schnyder, 1993). Reducing the assimilate availability by shading the plant during seed filling led to a sharp fall in stem reserves in L. perenne but had a small effect on seed yield (Warringa \& Marinissen, 1996). This indicates support from stem reserves to seed yield.

The relatively low utilisation of available stem reserves during seed filling indicates that seed yield potential is high and not limited by the availability of assimilates. The results presented here have shown that the stem of the flowering tiller does not compete with the filling seeds, but contains large amounts of soluble sugars and exports assimilates as seed filling proceeds. The seeds do not seem to be able to use these reserves fully. 


\section{Acknowledgements}

The authors wish to thank P.C. Struik (Department of Agronomy, WAU), A.J.C. De Visser, W.J.M. Meijer, H.J. Bouwmeester and R. Booij (AB-DLO) for critically reading the manuscript. We thank J.P. Dirkzwager for the drawing of Figure 1. Financial support from the Netherlands Grain Centre (NGC) is gratefully acknowledged.

\section{References}

Austin, R.B., C.L. Morgan, M.A. Ford \& R.D. Blackwell, 1980. Contributions to grain yield from preanthesis assimilation in tall and dwarf barley phenotypes in two contrasting seasons. Annals of Botany 45: 309-319.

Bidinger, F., R.B. Musgrave \& R.A. Fischer, 1977. Contribution of stored pre-anthesis assimilate to grain yield in wheat and barley. Nature 270: $431-433$.

Boutton, T.W., 1991. Stable carbon isotope ratios of natural materials: I. Sample preparation and mass spectrometric analysis. In: D.C. Coleman and B. Fry (Eds.), Carbon isotope techniques. Academic Press Inc., San Diego, pp. 155-171.

Clemence, T.G.A. \& P.D. Hebblethwaite, 1984. An appraisal of ear, leaf and stem ${ }^{14} \mathrm{CO}_{2}$-assimilation, ${ }^{14} \mathrm{C}$-assimilate distribution and growth in a reproductive seed crop of amenity Lolium perenne. Annals of Applied Biology 105: 319-327.

Colvill, K.E. \& C. Marshall, 1984. Tiller dynamics and assimilate partitioning in Lolium perenne with particular reference to flowering. Annals of Applied Biology 104: 543-557.

Elgersma, A., 1990. Genetic variation for seed yield in perennial ryegrass (Lolium perenne L.). Plant Breeding 105: 117-125.

Elgersma, A. \& R. Sniezko, 1988. Cytology of seed development related to floret position in perennial ryegrass (Lolium perenne L.). Euphytica S:59-68.

Evans, J.R., 1989. Photosynthesis and nitrogen relationships in leaves of $\mathrm{C}_{3}$ plants. Oecologia $78: 9-19$.

Farrar, J.F., 1992. The whole plant: carbon partitioning during development. In: C.J. Pollock, J.F. Farrar \& A.J. Gordon (Eds.), Carbon partitioning within and between organisms. Bios Scientific Publishers, Oxford, pp.163-179.

Griffith, S.M., 1992. Changes in post-anthesis assimilates in stem and spike components of Italian ryegrass (Lolium multiflorum Lam.). I. Water soluble carbohydrates. Annals of Botany 69: 243-248.

Hall, A.J., D.J. Connor \& D.M. Whitfield, 1989. Contribution of pre-anthesis assimilates to grain-filling in irrigated and water-stressed sunflower crops. I.Estimates using labelled carbon. Field Crops Research 20: 95-112.

Hampton, J.G., T.G.A. Clemence \& P.D. Hebblethwaite, 1983. Nitrogen studies in Lolium perenne grown for seed. IV. Response of amenity types and influence of a growth regulator. Grass and Forage Science 38: 97-105.

Hebblethwaite, P.D., D. Wright \& A.. Noble, 1980. Some physiological aspects of seed yield in Lolium perenne L. (perennial ryegrass). In: P.D. Hebblethwaite (Ed.), Seed Production. Butterworths, London, pp. 71-90.

Jenner, C.F., 1980. Effects of shading or removing spikelets in wheat: testing assumptions. Australian Journal of Plant Physiology 7: 113-121.

Marshall, C., 1985. Developmental and physiological aspects of seed production in herbage grasses. Journal of Applied Seed Production 3: 43-49.

Marshall, C. \& D. Ludlam, 1989. The pattern of abortion of developing seeds in Lolium perenne L. Annals of Botany 63:19-27.

Ong. C.K., K.E. Colvill \& C. Marshall, 1978a. Assimilation of ${ }^{14} \mathrm{CO}_{2}$ by the inflorescence of Poa annua L. and Lolium perenne L.. Annals of Botany 42: 855-862.

Ong, C.K., C. Marshall \& G.R. Sagar, 1978b. The physiology of tiller death in grasses. 2.Causes of tiller death in a grass sward. Journal of the British Grassland Society 33: 205-211.

Parsons, A.J. \& M.J. Robson, 1981. Seasonal changes in the physiology of S.24 perennial ryegrass 


\section{J.W. WARRINGA AND M.J. MARINISSEN}

(Lolium perenne L.). 3. Partitioning of assimilates between root and shoot during the transition from vegetative to reproductive growth. Annals of Botany 48: 733-744.

Payne, R.W., P.W. Lane, A.E. Ainsley, K.E. Bicknell, P.G.N. Digby, S.A.. Harding, P.K. Leech, H.R. Simpson, A.D. Todd. P.J. Verrier \& R.P. White, 1987. Reference Manual Genstat 5 Committee Rothamsted Experimental Station. Clarendon Press, Oxford, 749 pp.

Ryle, G.J.A., 1967. Effects of shading on inflorescence size and development in temperate perennial grasses. Annals of Applied Biology 59: 297-308.

Ryle, G.J.A., 1970. Distribution patterns of assimilated ${ }^{14} \mathrm{C}$ in vegetative and reproductive shoots of Lolium perenne and Lolium temulentum. Annals of Applied Biology 66: 155-167.

Schnyder, H., 1993. The role of carbohydrate storage and redistribution in the source-sink relations of wheat and barley during grain filling - a review. New Phytologist 123: 233-245.

Sinclair, T.R. \& T. Horie, 1989. Leaf nitrogen, photosynthesis and crop radiation use efficiency: A review. Crop Science 29: 90-98.

Spiertz, J.H.J. \& J. Ellen, 1972. The effect of light intensity on some morphological and physiological aspects of the crop perennial ryegrass (Lolium perenne L. var. 'Cropper') and its effects on seed production. Netherlands Journal of Agricultural Science 20: 232-246.

Steiner, A.A., 1984. The universal nutrient solution. In: ISOSC Proceedings of the $6^{\text {th }}$ International Congress on Soilless Culture. Wageningen, pp. 633-649.

Svejcar, T.J., T.W. Boutton \& J.D. Trent, 1990. Assessment of carbon allocation with stable carbon isotope labeling. Agronomy Journal 82: 18-21.

Swank, J.C., F.E. Below, R.J. Lambert \& R.H. Hageman, 1982. Interaction of carbon and nitrogen metabolism in the productivity of maize. Plant Physiology 70: 1185-1190.

Warringa, J.W. \& A.D.H. Kreuzer, 1996. The effect of new tiller growth on carbohydrates, nitrogen and seed yield per ear in Lolium perenne L. Annals of Botany 78: 749-757.

Warringa, J.W. \& M.J. Marinissen, 1996. The effect of light intensity after anthesis on dry matter distribution and seed yield of Lolium perenne L. Grass and Forage Science 51: 103-110.

Warringa, J.W., P.C. Struik \& A.D.H. Kreuzer, 1998. The pattern of flowering, seed set, seed growth and ripening along the ear of Lolium perenne L. Australian Journal of Plant Physiology (in press).

Williams, S. (ed.), 1984. Official methods of analyses of the association of official analytical chemists. The William Byrd Press Inc, Richmond.

Yamagata, M., H. Kouchi \& T. Yoneyama, 1987. Partitioning and utilization of photosynthate produced at different growth stages after anthesis in soybean (Glycine max L. Merr.): Analysis by long-term ${ }^{13} \mathrm{C}$-labelling experiments. Journal of Experimental Botany 38: 1247-1259. 